\title{
Mujeres estructuralmente viajeras: estereotipos y estrategias
}

\author{
Entrevista con Dolores Juliano
}

Este texto es la transcripción, a modo de discurso vertebrado, de la entrevista realizada a la antropóloga Dolores Juliano (Universitat de Barcelona. Departament d'Antropologia) sobre los temas más relevantes de los diversos artículos que constituyen este monográfico. La entrevista fue realizada por Kàtia Lurbe (Universitat Autònoma de Barcelona. Universidad de Wanwick) el 23 de septiembre de 1999.

\section{La inmigración nunca es un fenómeno asexuado}

¿Qué tal iniciar nuestro recorrido alrededor de los temas tratados en el presente monográfico con la importancia de introducir en los estudios sobre migración la perspectiva de género?

El tema del género es un tema tradicionalmente poco tratado en los trabajos sobre migraciones. Los artículos sobre inmigración realizados desde una perspectiva de género nos llegan con relativa tardanza con respecto a la tradición de estudios sobre los movimientos migratorios. Es más, la visibilidad social de las mujeres inmigrantes continúa siendo escasa en relación con la visibilidad social de los hombres inmigrantes. Cabe destacar que introducir la variable de género no consiste en aportar un dato más, sino que obliga a repensar todo el modelo de inmigración. En principio, las mujeres emigran en muchos casos por motivos diferentes a los de los hombres y a través de redes distintas. Por otra parte, la visión social de la sociedad de llegada de las mujeres inmigrantes (esto es, los problemas, los riesgos e incluso la significación de la emigración misma) es diferente. Por consiguiente, no se trata simplemente de completar los estudios, sino que al introducir la variable de género se cambia en una medida bastante importante el significado mismo de los datos.

Por poner un ejemplo, en la inmigración norteafricana (la inmigración más importante numéricamente en España) y en el caso específico de Cataluña, tiende a igualarse el número de hombres y de mujeres. Un análisis de las motivaciones de la inmigración de las mujeres procedentes del norte de África nos indicaría que gran parte de estas mujeres que emigran lo hacen 
movidas por problemáticas de género. Entre tales mujeres encontraríamos viudas, madres solteras o mujeres que desean continuar sus estudios. Aparte de la motivación migratoria debida a cambios políticos que afectan desigualmente a hombres y mujeres, existen también determinantes económicos en la emigración que influyen de manera diferente según género. La demanda de servicio doméstico en los países de la Europa del sur sirve como un elemento de atracción diferencial de mano de obra femenina. Cabe destacar, al respecto, que la situación de las áreas rurales de los países de origen — fundamentalmente si la propiedad de la tierra está en manos masculinaspuede significar que las mujeres que no tienen una inserción familiar clara queden excluidas del acceso de la tierra. Se producen, pues, procesos específicos de expulsión, así como procesos específicos de demanda, que influyen en una selección de la inmigración por género. La inmigración nunca es un fenómeno asexuado, responde de manera bastante importante a determinantes de género.

\section{Mujeres estructuralmente viajeras}

Los artículos que componen el presente monográfico muestran como la introducción de la perspectiva de género en los estudios sobre inmigración pone en evidencia numerosos estereotipos sobre la imagen de las mujeres inmigrantes. Al respecto, el perfil de las mujeres inmigrantes no es el de mujeres "dependientes", "analfabetas" en algunos casos y "perdidas", sino de mujeres que emigran solas, con un proyecto migratorio autónomo. Asi pues, un creciente número de mujeres provienen de medios urbanos y con niveles de instrucción y calificación más elevados que los de la media de sus propios paises.

La idea de la inmigración femenina como dependiente de la masculina se apoya en un estereotipo muy consolidado, según el cual el hombre es más móvil geográficamente. La mujer se caracterizaría por permanecer, mientras que el hombre tendría unos itinerarios autónomos más amplios. Sin embargo, esto es falso en su conceptualización misma, dado que la inmensa mayoría de nuestras sociedades son patrilocales, lo que significa que el modelo tradicional de mujer es el de la mujer que abandona su hogar de origen para ir a vivir al lugar de su marido. Así, mientras que el hombre podía pasar toda la vida en el grupo en el cual nacía, la mujer era emigrante por definición, puesto que al casarse debía cambiar de lugar.

Este fenómeno ha implicado que estudios antropológicos como los de Lévi-Strauss hayan puesto especial énfasis a la circulación de las mujeres entre los grupos. Así pues, podemos hablar de mujeres estructuralmente viajeras en contraposición a la imagen estereotipada de mujeres accidentalmente viajeras. Sin embargo, esta movilidad espacial resulta absolutamente invisible. Curiosamente, la movilidad femenina se tiene en cuenta en la legislación, pero con efectos discriminadores. A modo de ejemplo, antes de la Constitución española de 1978, las mujeres que emigraban y se casaban con hombres extran- 
jeros perdían la nacionalidad española. Todo ello nos leva a la conclusión que la concepción de «la mujer como estable en un lugar» se refiere a la mujer que se ha casado y que la idea del hombre que cambia de domicilio significaría que posteriormente arrastraría a la mujer. Este estereotipo no se confirma con los datos reales. Estudios muy interesantes realizados en España, tales como el de Carmen Gregorio sobre las dominicanas, o trabajos sobre las filipinas o las peruanas en el caso de Àngels Escrivá, señalan que las mujeres inmigrantes no vienen como inmigración de arrastre, sino que ellas mismas son las puntas de lanza de una inmigración que posteriormente termina o no arrastrando a los hombres de su familia. En términos generales, la idea de la mujer que viene simplemente por reagrupamiento familiar es una idea falsa, aunque es cierto que se corresponde con las prácticas de algunos grupos en particular.

\section{La inmigración connota una pérdida no solamente de espacios sociales, sino también de categorías laborales}

Los datos referentes a la ocupación de las mujeres inmigrantes en la Europa del sur revelan que éstas se localizan dentro del mercado laboral en el servicio doméstico y en la prostitución, aunque también trabajen en la industria del turismo, en empresas de limpieza, en hospitales y clinicas como enfermeras o auxiliares, etc. Las mujeres inmigrantes se insertan, pues, en sectores laborales considerados predominantemente femeninos. Según su opinión, ¿se está produciendo una etnización de los servicios de reproducción social?

En líneas generales, toda inmigración se caracteriza por ocupar los huecos laborales que son rechazados por la población receptora. Desde este punto de vista, este fenómeno no es una condición particular de la inmigración femenina. Sin embargo, esto se produce a su vez con una especificación de género: mientras que los hombres inmigrantes ocupan los nichos laborales que no interesan a los hombres autóctonos, las mujeres inmigrantes ocupan los que no interesan a las mujeres autóctonas. En la medida en que en las sociedades de acogida se produce una desigualdad sexual en el mercado laboral, basada en que las mujeres ocupen los puestos de trabajo de menor prestigio social y más bajos ingresos, no es de extrañar que a las mujeres inmigrantes les sean reservados estos puestos. Es decir, las tareas que tradicionalmente venían asignadas a las mujeres, fundamentalmente las más bajas en la escala social, son las que están siendo ocupadas por las inmigrantes. Desde este punto de vista podemos hablar de una etnización de las tareas de reproducción social. Sin embargo, quiero señalar que esto no es específico de las mujeres. En el caso de la inmigración peruana, los hombres también se dedican en una medida bastante importante a los trabajos de cuidado personal, especialmente al servicio doméstico interno. Respecto a la prostitución, existe una prostitución masculina, fundamentalmente travestis, que cuenta con un contingente bastante significativo de origen latinoamericano. 
En el caso de las inmigrantes por motivos económicos, ¿el pasar el "Rio Grande Europeo" supone un progreso en términos tanto materiales como de realización personal, en cuanto a mayor emancipación y ascenso en la escala social respecto a su situación en sus respectivos paises de origen?

Esto tiene una doble lectura. Dado que la gente emigra y se queda en el lugar de inmigración, es evidente que hay ciertas ventajas comparativas. Por tanto, aunque las inmigrantes ocupen lugares laborales rechazados por las mujeres de la sociedad de acogida, es evidente que comparando con los ingresos que podrían tener en su sociedad de origen, normalmente obtienen una cierta ventaja relativa a este nivel. Sin embargo, es cierto que, prácticamente en todos los casos, la inmigración connota una pérdida no solamente de espacios sociales, sino también de categorías laborales. Normalmente toda la inmigración está subempleada en términos de su capacitación de origen. El descenso del nivel ocupacional y del prestigio social se compensa de alguna manera en términos de mayores ingresos que posibilitan la capacidad de ahorro, que a su vez permiten, en algunos casos, retornar a la sociedad de origen con una autonomía mayor (éste sería el caso de las dominicanas que ahorran para la compra de una vivienda y de un negocio) o, en otros casos, para costearse estudios o desarrollar algún proyecto autónomo en el lugar de acogida. En conclusión, si bien la situación de las mujeres inmigrantes cambia en relación a la que tenían en sus sociedades de origen, dicho cambio no es positivo en todos sus elementos.

Respecto a las posibilidades de autodeterminación, en las sociedades en las cuales el control sobre las mujeres es más rígido la distancia implica ciertas posibilidades de autonomía, pero no hay que idealizar demasiado. Con esto no me refiero solamente a las sociedades musulmanas, sino en líneas generales a todas las sociedades tradicionales, las cuales ejercen un fuerte control social sobre las mujeres y, en especial, sobre la sexualidad femenina, tal como es el caso de «nuestras» sociedades tradicionales. En el caso de las dominicanas, por ejemplo, el control social sigue siendo bastante fuerte, porque todas las mujeres que emigran provienen de una misma área, se conocen todas, siguen en comunicación permanente con sus familias. En consecuencia, estas mujeres siguen formando parte de redes sociales que, por una parte, son de apoyo, pero, por otra, generan fuerte control y limitan su capacidad de movimiento. Por otro lado, el conseguimiento de cierto nivel económico. Así puede permitirles también conseguir el levantamiento de determinados tabúes. Trabajos como el de Ángeles Ramírez demuestran que marroquíes que ejercen la prostitución en el lugar de acogida no tienen la misma desvalorización social que tendrían si practicasen la misma actividad en la sociedad de origen.

Hablemos de la mirada de la sociedad de recepción respecto a la población inmigrante. En su libro Las que saben. Subculturas de mujeres (1998, de la editorial Horas y horas), escribio: «sospechosas de dedicarse a trabajos ilegales y de procrear en el seno del mundo rico pequeños que muestren en sus pieles oscuras que el Tercer Mundo existe, las mujeres tienen mayor cantidad de barreras a la inmigración que 
los hombres y se desarrollan sobre ellas estereotipos más desvalorizadores (se les considera ignorantes, sumisas e hiperreligiosas) aunque suscitan menos agresividad». ¿A qué se debe la exclusión de la persona inmigrante si lo que se da no es una competencia laboral sino más bien una complementariedad?

En mi opinión, la lectura distorsionada tiene más que ver con los conflictos internos dentro de la sociedad receptora que con el problema de la inmigración en sí misma. La inmigración es poco significativa cuantitativamente en España. En Cataluña, donde su peso es mayor, no llega ni al 2\% de la población total. Es más, la inmigración proviene mayoritariamente de los países ricos. Pero tratemos de comprender qué es lo que alimenta la construcción distorsionada sobre la inmigración. Al respecto, es cómodo socialmente disponer de algún sector al cual atribuir los problemas sociales. Es decir, si hablamos del paro y la precariedad laboral, en lugar de cuestionar el tipo de industrialización que se está llevando a cabo, el tipo de opciones laborales, el porqué se mantienen los contratos por muchas horas y las horas extras en lugar de subdividir éstas en mayor empleo, es mucho más sencillo señalar que el paro se produce porque «los/as inmigrantes vienen a quitarnos nuestros puestos de trabajo». Desde este punto de vista, no es necesario hacer ninguna crítica a la propia estructura social. El inmigrante cumple, pues, una doble función: se ocupa de las tareas que la población de acogida no tiene interés en realizar $y$, a su vez, asume la conflictividad y los problemas que la sociedad de acogida tiene y que se evita plantear como tales problemas en la medida que se deriva hacia otros sectores de población.

En la lectura problematizada de la inmigración contribuyen algunos acuerdos internacionales que hablan literalmente de los problemas de la inmigración, la droga y la inseguridad ciudadana, poniendo estos temas diversos en el mismo saco. Las políticas mismas que se realizan tienden a facilitar este tipo de rotulación negativa. Esto sería el caso de cuando se resaltan las muertes de inmigrantes en las pateras, así como las medidas que toma el gobierno para impermeabilizar las fronteras, lo cual lleva a pensar a la gente que dado que los gobernantes dedican su tiempo y esfuerzo a impedir que esta gente entre será porque esta gente es peligrosa. La sanción policial contra la inmigración legal, que no tiene más delito que no cumplir las especificaciones que la ley expone en términos de papeles, transforma lo que es un problema administrativo en lo que podríamos llamar un problema de tipo policial. Todo esto hace que se tienda a ver la inmigración como portadora potencial de conflictividad social.

¿Es incompatible profesar la religión islámica y tener un grado elevado de autodeterminación y reivindicaciones de género?

¿Qué opina sobre el temor general hacia ellla inmigrante musulmán, cuyo sintoma se manifestaría al hacer más visible la población inmigrante de origen magrebi?

En cuanto a la inmigración musulmana, los números no solamente no son demasiados significativos por más que la inmigración musulmana vaya cre- 
ciendo, sino que no se correlacionan con un peligro real. Existe una tendencia a construir el nosotros en contraposición a un otro. El nosotros se construye mediante la atribución de una cantidad de características positivas, que nos atribuimos a nosotros mismos. Tradicionalmente, mientras que en el imaginario centroeuropeo esta función de alteridad fue asumida por los judíos con las consecuencias que conocemos, en el imaginario español peninsular dicha función del otro se la asignó a los moros. España se constituyó como tal luchando contra una presunta invasión árabe. Esto vendría claramente ilustrado recordando que Santiago, patrón de España, es «Santiago mata-moros»; los reyes importantes, esto es los Reyes Católicos y Felipe II, se han caracterizado por su expulsión del moro y del morisco. Posteriormente, los distintos gobiernos del siglo pasado llevaron a cabo campañas civilizadoras en el norte de África y la apropiación de territorios que estaban en manos musulmanas. En términos del imaginario progresista, a estas discriminaciones tradicionales se agrega el hecho que Franco viene apoyado por una guardia mora, y por consiguiente se ven, a su vez, los moros como enemigos del progresismo republicano. A partir de todos estos elementos se configuran estereotipos fuertemente desvalorizadores. Algunos investigadores, tales como Eloy Martínez, han trabajado durante los últimos años juntando gran cantidad de representaciones gráficas que testimonian cómo se han mostrado tradicionalmente los moros. Sabemos que se ha manifestado al respecto una especie de apología de la desvalorización. La gente se ha acostumbrado a ver a los musulmanes a través de estas imágenes como personas potencialmente peligrosas. Cuando a partir de la década de los ochenta a este imaginario tradicional, que no tiene nada que ver con ninguna inmigración, se le agrega el hecho de que comienza una inmigración real de población musulmana, se actualizan los viejos fantasmas. Dicha actualización va subrayada posteriormente por una política internacional, en la cual tras el derrumbe del Este como enemigo Occidente se busca un nuevo enemigo. Occidente comienza, pues, a demonizar algunas concreciones islámicas (recuérdense los casos de conflicto con Irán, Irak y Libia). Así pues, el nuevo enemigo no es sino un viejo enemigo: el mundo musulmán como el otro próximo y opuesto ante el cual hay una larga historia de enfrentamiento. Desde este punto de vista, es importante señalar el papel de los medios de información - o desinformación - en la presentación de una imagen homogeneizada y negativa de lo musulmán. En el discurso mediático, los musulmanes se caracterizan por ser fanáticos fundamentalistas, agresivos y discriminadores con respecto a las mujeres. Todos estos rasgos definitorios les son atribuidos globalmente, sin tener en cuenta que cualquier sistema religioso genera sus propios fanáticos. Cabría recordar que nosotros contamos con una larga experiencia de fanatismo religioso católico. De hecho, el islam, históricamente, no se ha caracterizado por su intolerancia, sino, por el contrario, por defender la convivencia de las distintas religiones.

Por otra parte, otros de los elementos que se le atribuyen al islam, como la discriminación de género, es algo en lo cual también nosotras tenemos una larga experiencia dentro de nuestra propia cultura. $\mathrm{Al}$ respecto, el islam no ha 
sido históricamente más discriminador con respecto a la mujer que las religiones cristianas. Sólo en las últimas décadas en la cuales hemos hecho un avance muy importante en términos de logros de género, nos hemos puesto por delante del término medio de las sociedades musulmanas en algunos aspectos. Personalmente me ha interesado estudiar la situación de la mujer en el islam. Por ello me interesó analizar alguna situación islámica en la cual las mujeres no estuvieran muy discriminadas. $\mathrm{Al}$ respecto, me resultó muy enriquecedor trabajar sobre las mujeres saharauis. Dicha experiencia me permitió ver cómo no es incompatible profesar una religión islámica y tener un grado elevado de autoafirmación y reivindicaciones de género.

\section{En lugar de estar tan aisladas como se piensa, las mujeres inmigrantes aprenden muy pronto a sacar partido de los servicios sociales}

Respecto a los servicios sociales asignados a la población inmigrante, ¿qué opina sobre el papel del denominado "tercer sector» en la colaboración entre instituciones públicas y privadas?

En este tema se da un doble problema. Por una parte, la función substitutoria de los servicios del bienestar es tomada por determinadas instituciones de solidaridad y de apoyo a la misma población de inmigrantes. Actualmente se está debatiendo de manera intensa si esta substitución es o no conveniente. En este caso, me gustaría matizar que si las instituciones de inmigrantes reciben financiación del Estado para la prestación de unos servicios, no habría ningún inconveniente en que la administración de estos recursos se realizara canalizada por distintos sectores. Lo importante es que dichos servicios lleguen a los distintos usuarios necesitados. Pero si la desimplicación del Estado significa la no derivación de recursos, entonces la situación cambia radicalmente.

En el caso particular de las mujeres inmigrantes, se han recogido datos que revelan (por ejemplo a partir de los estudios de Adriana Kaplan) que dichas mujeres inmigrantes, incluso las que conocen poco el idioma, son usuarias recurrentes de los servicios de salud y servicios asistenciales. Estos datos nos indican que en lugar de estar tan aisladas como se piensa, las mujeres inmigrantes aprenden muy pronto a sacar partido de estos servicios. Proporcionalmente, las mujeres son, pues, usuarias en mayor cantidad que los hombres inmigrantes de los servicios asistenciales. En consecuencia, podemos derivar la idea que estas mujeres se manejan mejor en el lugar de acogida.

Ahora bien, una última cuestión es saber si estos servicios tienen realmente en cuenta sus necesidades. Éste es, a mi parecer, el punto más difícil, porque tendemos a considerar que lo que conviene a los inmigrantes en general es aquello que nosotros pensamos que les conviene. Solemos dar pocas oportunidades a la población inmigrante para que ella misma exprese sus deseos y necesidades. Con ello corremos el riesgo de ofrecer servicios o actividades que para ellas no resultan significativos y no ofrecer aquéllas que ellas realmente utilizarían. Un ejemplo ilustrativo sería el de ofrecer servicios mixtos para hom- 
bres y mujeres a integrantes de sociedades en las cuales se pueden realizar algunas de las actividades con la condición de que se realicen por separado. En dicho caso, si nosotros ofrecemos dichas actividades en conjunto, lo único que conseguimos es que las mujeres de estos sectores no acudan. Por concretar un poco más, las mujeres musulmanas tienen como ámbito de encuentro los baños públicos, el hammam. Por tanto, si nosotros queremos que tengan lugares de reunión, no estaría mal que organicemos para ellas estos baños públicos en lugar de insistir en que acudan a otros lugares de reunión que no son aquéllos que acostumbran frecuentar.

La mujer inmigrante es una mujer que ha «abandonado» el lugar de origen y que está formando unas nuevas estrategias de convivencia

Por último, me gustaría retomar uno de los temas principales de su libro Las que saben. Subculturas de mujeres. En el presente monográfico destaca el hecho de la inexistencia de asociaciones de mujeres inmigrantes que se ocupen de asuntos específicos, aunque se da paradójicamente una elevada participación de mujeres en el movimiento asociativo. Encuentro especialmente interesante el enfoque que usted propone en su libro en relación con esta cuestión. En vez de definir dicha situación en términos de pasividad acorde con la visión más generalizada, su propuesta radica en hacer visibles las distintas estrategias utilizadas por las mujeres. Esto es, a lo largo de toda una historia de padecer discriminación social, las mujeres han desarrollado estrategias diversas de supervivencia y autoafirmación: por un lado, las reivindicaciones implícitas más actuadas que declaradas, propias de la sociedad tradicional $y$, por otro, las reivindicaciones explícitas, aquéllas desarrolladas alrededor del movimiento feminista.

Lo cierto es que nosotras estamos acostumbradas a hablar de reivindicaciones en referencia a aquéllas que se plantean como tales, cuando en realidad toda conducta es un discurso. Por consiguiente, considero más importante el ver lo que la gente hace realmente que aquello que expresa sobre lo que hace. En muchos casos, el discurso tiende a minimizar o a disimular la actividad que realmente se realiza, más que a explicitarla. En cuanto a las reivindicaciones de género de las mujeres inmigrantes, quisiera destacar que dichas mujeres están inmersas en un proceso de transformación, el cual no depende de los discursos explícitos de la sociedad de acogida, sino que se organiza desde antes de su llegada. La mujer inmigrante es una mujer que ha abandonado el lugar de origen y está formando unas nuevas estrategias de convivencia. Esta mujer ha dado, pues, muchísimos pasos, en el sentido de lo que podríamos llamar la autonomía, la toma de decisiones, el asumir riesgos y responsabilidades. No estamos ante una mujer tradicional a la cual el mundo se le abre al llegar a la sociedad receptora, sino que llega aquí porque tiene ya el mundo abierto. De lo contrario, no se movería del lugar de origen. En estas condiciones y con estas experiencias previas, las mujeres seleccionan de la sociedad de acogida aquello que resulta compatible con sus sistemas de supervivencia y sus estrategias 
previas, afianzan algunos elementos, dejan de lado otros. Estas lecturas y reestructuraciones no forzosamente se llevan a cabo en el sentido que nosotros pensamos que se van a producir. Por ejemplo, la tesis doctoral de Lacombe, que estoy leyendo estos días y que se defenderá en Valencia próximamente, señala que en general para la población musulmana vemos como muchas de las personas que no eran practicantes en su sociedad de origen se transforman en practicantes en la sociedad de acogida. Una causa de ello es que asistir a la mezquita es un modo de encontrarse con los otros, afirmar su identidad, etc. El impacto de la inmigración no va siempre en el sentido de hacer sus costumbres más semejantes a las nuestras. En algunos casos puede servir para reafirmar algunas de las conductas anteriores.

Pienso que lo interesante con relación a la mujer inmigrante, pero también, con respecto a los grupos subalternos, es, por una parte, analizar críticamente lo que hacemos nosotros con respecto a ellas (cómo las vemos, qué lecturas hacemos de ellas, cuáles son nuestros estereotipos, cuáles son los caminos que les estamos dando). Por otra parte, desde mi punto de vista, lo más importante es comprender qué hacen ellas con la nueva situación (cómo la ven, cómo la viven, desde qué punto de vista les resulta gratificante, desde cuál les resulta penosa, etc.). En breve, aquello que me parece más interesante es analizar cuales son sus estrategias. Estos es lo que posibilita que el trabajo sobre mujeres inmigrantes no sea un trabajo meramente didáctico en relación con el hecho de enseñarles cuales son los servicios públicos a su disposición, sino un estudio sobre la forma en que las mujeres inmigrantes estructuran su propio mapa de la ciudad y cuales son las puertas que ellas mismas perciben abiertas para sí en la sociedad de acogida. Es importante analizar también como se manejan en términos de su propia autoestima. Es más, lo único que se puede hacer con un colectivo es establecer un diálogo, lo cual requiere partir de la idea que ellas están actuando de una manera eficaz sobre los recursos posibles.

\section{Dolores Juliano, a modo de conclusión, ¿quisiera añadir algunas palabras en torno a las mujeres inmigrantes en Europa del Sur?}

$\mathrm{Al}$ respecto pienso que cabría subrayar que una parte importante de la investigación que se hace sobre inmigración femenina se realiza desde la inmigración femenina; es decir, desde las inmigrantes externas e internas que de alguna manera tienen conocimiento privilegiado de la experiencia de la inmigración misma. Cabe destacar también que se está generalizando la idea de que la inmigración femenina requiere estudios específicos, ya que no es un apéndice de la inmigración masculina. Estos serían, pues, los elementos de los que debe constar un número dedicado a la inmigración femenina, elementos que encontramos en el conjunto del presente monográfico. 